\title{
SELEÇÃO DE BACILLUS SPP. RESISTENTES AO SUCO GÁSTRICO
}

\author{
Natália Barreiros Alves ${ }^{1}$; Elisa Teshima ${ }^{2}$ \\ 1. Bolsista PIBIC/FAPESB, Graduanda em Engenharia de Alimentos, Universidade Estadual de Feira de Santana, e- \\ mail: barreiros.alves@ hotmail.com \\ 2. Orientadora, Departamento de Tecnologia, Universidade Estadual de Feira de Santana, e-mail: eteshima@uefs.br
}

PALAVRAS-CHAVE: Isolamento; Bacillus; Probiótico.

\section{INTRODUÇÃO}

Probióticos são alimentos que apresentam microrganismos vivos, não patogênicos e que, quando ingeridos numa concentração diária específica, exercem efeitos benéficos à saúde do consumidor, tais como: modulação do sistema imune, redução de colesterol sérico, prevenção de doenças intestinais como diarreia ou intolerância à lactose, e aqueles associados ao efeito barreira (LEE; SALMINEN, 2009). Os microrganismos comumente associados como probióticos são as bactérias Grampositivas, principalmente, às pertencentes aos gêneros Lactobacillus, Bifidobacterium e Bacillus (HONG et al., 2008).

As espécies do gênero Bacillus possuem várias vantagens sobre outros microrganismos não-formadores de esporos, tais como: 1) Bacillus podem sobreviver em alimentos que requerem processamento a elevada temperatura e pressão, 2) Sobrevivem melhor nas condições do trato gastrointestinal, 3) Possuem uma vida de prateleira longa e permanece viável durante todo o seu período, tanto nas condições de temperatura ambiente e refrigerados, e 4) Devido à sua melhor capacidade de sobrevivência, a efetiva dose necessária para Bacillus como suplementos probióticos é menor (SOROKULOVA et al., 2013).

Das mais de 300 espécies de Bacillus conhecidas, apenas algumas são usadas como probióticos para consumo humano, que incluem o $B$. subtilis, B. licheniformis, $B$. clausii, B. coagulans, B. pumilus, e B. laterosporus (SOROKULOVA et al., 2013). Produtos contendo endosporos de Bacillus são utilizados comercialmente como probióticos, contendo uma única dose de $10^{9}$ esporos/g ou ml. Produtos desta natureza já estão disponíveis no mercado do Japão, Rússia e recentemente nos EUA. Diante do avanço de conhecimento nesta área de probióticos, este trabalho teve como objetivo o isolamento e a seleção de Bacillus para utilização em produtos probióticos.

\section{METODOLOGIA}

1. Isolamento de Bacillus ssp. de alimentos desidratados

Para realização do isolamento do microrganismo de interesse, foi utilizado como amostra: urucum, pimenta do reino, cominho, orégano, açafrão da terra, soja fermentada (natoo), polpa de umbu, farinha de tapioca e mistura pronta para vatapá. As amostras diluídas foram pasteurizadas a $80^{\circ} \mathrm{C}$ por 10 minutos, resfriadas e tratadas em solução alcoólica 50\% por uma hora, para germinação dos esporos (FRITZE; PUKALL, 2012). Este preparado foi submetido ao plaqueamento em superfície de agar MYP (Manitol Gema de ovo Polimixina), seguido de incubação a $37^{\circ} \mathrm{C}$ por 24 a 48 horas. Colônias com características distintas foram isoladas, transferidas para caldo nutriente e incubadas a $37^{\circ} \mathrm{C}$ por $24 \mathrm{~h}$, seguidas de estria por esgotamento de inóculo em agar nutriente, com incubação a $37^{\circ} \mathrm{C}$ por $24 \mathrm{~h}$. Após verificação da pureza das culturas, estas foram submetidas à coloração de Gram, coloração de esporos e ao teste de catalase.

\section{Coloração de Gram e caracterização morfológica dos isolados}


Foram realizados esfregaços de cada cultura isolada, em lâminas, com posterior coloração de Gram e coloração de esporos, seguida da observação em microscópio com aumento de 100X. Para cada cultura isolada foram observadas as características morfológicas, tipo de agrupamento, presença de esporos e coloração de Gram. A partir dos resultados de coloração e morfologia dos isolados, aqueles que possuíam as características desejadas recebiam códigos para seguir até a próxima etapa.

\section{Caracterização bioquímica dos isolados}

Os isolados bacterianos com morfologia de bacilos, esporulados, Gram positivos e catalase positivos foram submetidos aos seguintes testes bioquímicos: Teste Voges-Proskauer (VP), redução do nitrato, motilidade, citrato, urease, hidrólise do amido, crescimento em $6,5 \%$ de $\mathrm{NaCl}$ e teste de crescimento em anaerobiose, de acordo com a metodologia descrita no compêndio de análise microbiológica de alimentos (APHA, 2001).

\section{Teste de resistência ao suco gástrico}

As culturas padronizadas (DO 0,9) foram inoculadas $(5 \% \mathrm{v} / \mathrm{v})$ em suco gástrico artificial (cloreto de sódio: 2,0g; pepsina: 3,2g; ácido clorídrico concentrado: 7,0 mL; água destilada: $1000 \mathrm{~mL}$; $\mathrm{pH}$ final de 2,0; 2,5 e 3,0) de acordo com Newmann e Ferreira (1995). A solução de suco gástrico foi esterilizada a frio (membranas de $0,45 \mathrm{~mm}$ ). As amostras de suco gástrico inoculadas foram incubadas a $37^{\circ} \mathrm{C}$ e a contagem de células viáveis foi realizada imediatamente e 180 minutos após a inoculação, em Agar Nutriente. O experimento foi realizado em três repetições.

A resistência ao suco gástrico foi determinada pelo índice de \% de sobrevivência, obtido pela seguinte fórmula:

$\%$ de Sobrevivência $=\underline{(\log U F C / m L}$ no tempo 3 horas $) \times 100$

( $\log \mathrm{UFC} / \mathrm{ml}$ no tempo inicial)

\section{Análise Estatística}

Os resultados obtidos no teste de resistência ao suco gástrico foram analisados estatisticamente pela ANOVA ao nível de confiança de $95 \%$ de probabilidade. Quando apresentaram significância, foi utilizado o Teste Scott-Knott para comparação entre médias de sobrevivência e entre os isolados. Os testes foram realizados no programa SISVAR versão 5.6, 2006.

\section{RESULTADOS E DISCUSSÃO}

Foram utilizadas 34 amostras de alimentos de origem vegetal e ao todo foram isoladas 73 colônias de características distintas, porém 24,66\% foram Gram negativas, $13,69 \%$ apresentaram catalase negativa, $34,25 \%$ não possuíram morfologia de bacilos e apenas $27,4 \%$ apresentaram as características desejadas de bacilos esporulados, Gram positivos e catalase positivo. Lago (2002) destaca que, os microrganismos que se apresentam na forma de bacilos Gram positivos e que possuem a característica de formar esporos podem pertencer a quatro diferentes gêneros: Bacillus, Sporolactobacillus, Clostridium e Desulfotomaculum. Os microrganismos do gênero Bacillus são aeróbicos ou facultativos e tem característica catalase positiva, apresentando atualmente mais de 300 espécies com características fenotípicas distintas, no entanto a classificação ao nível de espécie é realizada por técnicas moleculares de DNA. Os isolados de Bacillus desta experimentação apresentaram características bioquímicas distintas que estão apresentadas no Quadro 1. 
Quadro 1 - Características bioquímicas das estirpes de Bacillus spp.

\begin{tabular}{|l|l|c|c|c|c|c|}
\hline Cultura & Origem & $\begin{array}{c}\text { Motilidad } \\
\text { e }\end{array}$ & Urease & $\begin{array}{c}\text { Crescimento } \\
\text { em 6,5\% de } \\
\text { NaCl }\end{array}$ & $\begin{array}{c}\text { Voges- } \\
\text { Proskauer }\end{array}$ & $\begin{array}{c}\text { Hidrólise de } \\
\text { Amido }\end{array}$ \\
\hline IA & Açafrão & + & - & - & - & + \\
\hline IB & Açafrão & + & - & - & + & + \\
\hline ID & Açafrão & + & - & + & + & - \\
\hline IF & Açafrão & - & - & + & + & - \\
\hline P1 & Umbu & + & - & - & - & + \\
\hline P2 & Umbu & + & - & - & - & + \\
\hline P3 & Umbu & - & - & - & - & + \\
\hline P4 & Umbu & - & - & - & - & + \\
\hline T1 & Tapioca & - & - & - & - & + \\
\hline T2 & Tapioca & - & - & - & - & + \\
\hline T3 & Tapioca & + & - & - & - & + \\
\hline V1 & Vatapá & + & - & - & - & + \\
\hline V2 & Vatapá & + & - & - & - & + \\
\hline V3 & Vatapá & + & - & - & - & + \\
\hline V4 & Vatapá & - & - & - & - & + \\
\hline V5 & Vatapá & + & - & - & - & + \\
\hline S1 & Soja & - & - & - & - & + \\
\hline S2 & Soja & + & - & - & - & + \\
\hline S3 & Soja & + & - & - & - & + \\
\hline S4 & Soja & - & - & - & - & - \\
\hline F0nt: El & + & - & & + \\
\hline
\end{tabular}

Fonte: Elaborado pela bolsista de Iniciação Científica.

Verificou-se que todas as culturas não crescem em anaerobiose bem como apresentaram resultado negativo para urease, nitrito e citrato. Apenas duas culturas apresentaram resistência a 6,5\% de $\mathrm{NaCl}$, três apresentaram capacidade para produzir acetoina (VP), três culturas não apresentaram capacidade de hidrolisar amido e a motilidade foi variável entre os isolados.

De acordo com Szajewska et al (2006), probioticos devem ser resistentes ao processamento, estável e permanecer viável, após exposição aos sucos digestivos e ser capaz de persistir no trato gastrointestinal. As culturas isoladas foram submetidas ao teste de resistência ao suco gástrico, cujos resultados estão apresentados na Figura 1.

Dentre todos os 20 isolados apenas 4 culturas apresentaram significativa sobrevivência ao suco gástrico após 3 horas em diferentes pHs. Verificou-se que entre os isolados, Bacillus S3 isolada da soja fermentada foi o mais resistente $(\mathrm{P}<0,05)$ a todos os valores de $\mathrm{pH}$ do suco gástrico, seguida de Bacillus IB. Foi observado também que a porcentagem de sobrevivência das culturas Bacillus S3 e Bacillus IB não diminuíram $(\mathrm{P}<0,05)$ com a redução do $\mathrm{pH}$, indicando que independente do valor do $\mathrm{pH}$ estomacal, as bactérias permanecerão viáveis em níveis adequados para atingirem o intestino. Desta forma, os resultados obtidos indicam que as culturas Bacillus S3 e Bacillus IB apresentam potencial para serem utilizados como probióticos. No entanto, testes adicionais como resistência aos sais biliares necessitam ser realizados. 


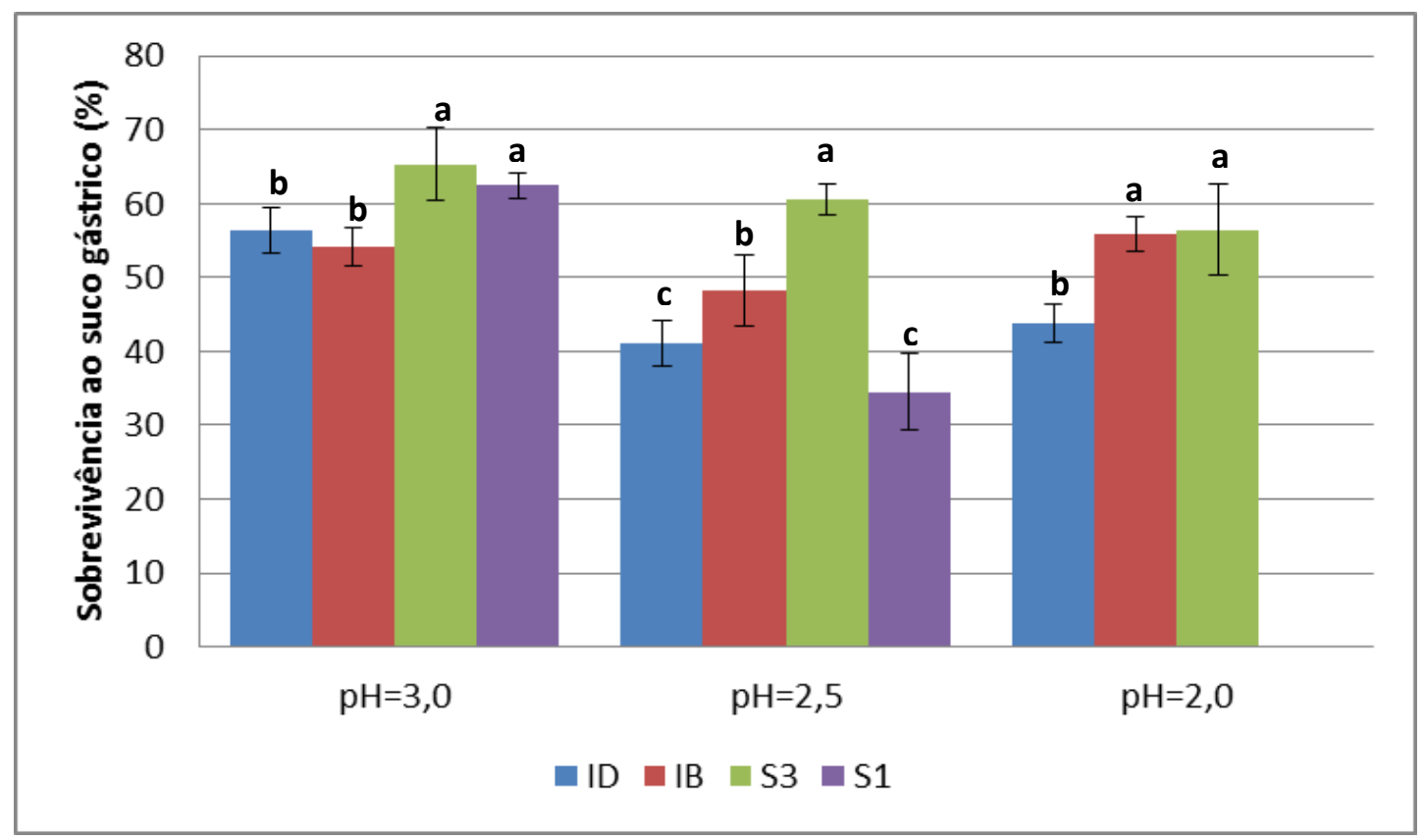

*Letras diferentes entre isolados para o mesmo valor de $\mathrm{pH}$ diferem estatisticamente $(\mathrm{P}<0.05)$

Figura 1. Sobrevivência de Bacillus ssp. após 3 horas em suco gástrico com diferentes $\mathrm{pH}$.

\section{CONSIDERAÇÕES FINAIS}

Foram isolados 20 culturas de Bacillus spp. de alimentos de origem vegetal e 4 culturas apresentaram significativa sobrevivência ao suco gástrico após 3 horas em diferentes pHs. A sobrevivência das culturas Bacillus S3 e Bacillus IB não diminuíram $(\mathrm{P}<0,05)$ com a redução do $\mathrm{pH}$, indicando que as mesmas apresentam potencial para serem utilizados como probióticos.

\section{REFERÊNCIAS}

APHA. American Public Health Association. Compendium of Methods for the Microbiological Examination of Foods. 4th ed., Washington, 676p., 2001.

FRITZE, D.; PUKALL, R. Culture media for Bacillus spp. and related genera relevant to foods. In: Handbook of culture media for food and water microbiology. 3 Ed., RSC Publishing, UK, p. 90-114, 2012.

HONG, H. A. et al. Bacillus subtilis isolated from the human gastrointestinal tract. Research in Microbiology, v. 160, p.134-143, 2009.

LEE, Y. K.; SALMINEN, S. Handbook of probióticos and prebiotics. 2nd. Ed. John Wilwy \&Sons, Inc. Hoboken, New Jersey, 2009.

NEWMANN, E.; FERREIRA, C. L. L. F. Lactobacillus acidophilus as dietary adjunct: "in vitro" susceptibility to gastric juice, bile salts, lysozyme and chemotherapeutic agents. Revista de Microbiologia, v. 26, p. 59-65, 1995.

SOROKULOVA, I. Modern Status and Perspectives of Bacillus Bacteria as Probiotics. J. Probiotic Health. 1: e106. 2013. Disponível em: <https://www.omicsonline.org/modern-status-and-perspectives-of-bacillus-bacteria-asprobiotics-2329-8901.1000e106.php?aid=21586>. Acesso em: 27 jun. 2017.

SZAJEWSKA H, SETTY M, MRUKOWICZ J, GUANDALINI S. Probiotics in gastrointestinal diseases in children: hard and not-so-hard evidence of efficacy. $J$ Pediatric Gastroenterol Nutr, v. 42, n. 5, p. 454-475, 2006. 